\title{
Current Challenges in Translating Tissue-Engineered Heart Valves
}

\author{
O. M. J. A. Stassen, PhD ${ }^{1, *}$ \\ D. E. P. Muylaert, MD, PhD ${ }^{2}$ \\ C. V. C. Bouten, $P h D^{1,3}$ \\ J. Hjortnaes, MD, PhD ${ }^{2,4}$
}

\author{
Address \\ ${ }^{*}, 1$ Department of Biomedical Engineering, Eindhoven University of Technology, \\ P0 Box 5135600 MB, Eindhoven, The Netherlands \\ Email: o.m.j.a.stassen@tue.nl \\ ${ }^{2}$ Department of Cardiothoracic Surgery, University Medical Center Utrecht, \\ Utrecht, The Netherlands \\ ${ }^{3}$ Institute for Complex Molecular Systems, Eindhoven University of Technology, \\ Eindhoven, The Netherlands \\ ${ }^{4}$ Regenerative Medicine Center Utrecht, University Medical Center Utrecht, \\ Utrecht, The Netherlands
}

Published online: 7 August 2017

(C) The Author(s) 2017. This article is an open access publication

This article is part of the Topical Collection on Valvular Heart Disease

Keywords Tissue-engineered heart valves $\cdot$ Heart disease $\cdot$ Valvular heart disease

\section{Opinion statement}

Heart valve disease is a major health burden, treated by either valve repair or valve replacement, depending on the affected valve. Nearly 300,000 valve replacements are performed worldwide per year. Valve replacement is lifesaving, but not without complications. The in situ tissue-engineered heart valve is a promising alternative to current treatments, but the translation of this novel technology to the clinic still faces several challenges. These challenges originate from the variety encountered in the patient population, the conversion of an implant into a living tissue, the highly mechanical nature of the heart valve, the complex homeostatic tissue that has to be reached at the end stage of the regenerating heart valve, and all the biomaterial properties that can be controlled to obtain this tissue. Many of these challenges are multidimensional and multiscalar, and both the macroscopic properties of the complete heart valve and the microscopic properties of the patient's cells interacting with the materials have to be optimal. Using newly developed in vitro models, or bioreactors, where variables of interest can be controlled tightly and complex mixtures of cell populations similar to those encountered in the regenerating valve can be cultured, it is likely that the challenges can be overcome. 


\section{Introduction}

Heart valve disease is a major health burden. The disease encompasses various defects of one or more of the four heart valves that, when in a severe state, can hamper proper blood flow through the heart. In the adult, the mitral valve and the aortic valve are the most commonly affected, with the main defects of the valves being either stenosis (incomplete opening) or regurgitation (incomplete closing). There are multiple causes of heart valve disease, with the most prevalent causes being bacterially induced acute rheumatoid fever (predominantly in lower-income countries) to age-related degeneration of the aortic and mitral valve (predominantly in higher-income countries) [1]. The main current therapeutic options are valve replacement or valve repair, with valve repair being an increasingly preferred therapy for mitral valve regurgitation [2]. Valves can be replaced by a mechanical valve or a bioprosthetic allograft (porcine) valve, or, in rare cases, a homograft (donor) valve. This replacement procedure is performed nearly 300,000 times globally each year [3]. Valve replacements are lifesaving, but not without complications: mechanical valves require lifelong anticoagulation, whereas allografts can undergo calcification or mechanical failure. This can result in a 50\% structural valve degeneration rate within 10 years [4]. In addition, both the mechanical replacement, the allograft, and the homograft have no capacity for growth, a major problem in the pediatric population suffering from congenital heart valve disease. To address this issue, the tissue-engineered heart valve (TEHV) has been under investigation for over 30 years as an alternative replacement therapy, starting with in vitro endothelialization of biological valves [5]. Initial trileaflet TEHV consisting of autologous cells seeded in vitro on a preshaped biodegradable scaffold to form a nonimmunogenic heart valve graft mimicking the native valve with a capacity to grow maintained functional up to 20 weeks [6]. In the development of TEHV, there has been much attention to the load-bearing function, extracellular matrix (ECM) formation, remodeling, and cellular behavior of TEHVs, all on a macroscopic scale of the tissue. This allowed the TEHVs to be improved for materials used, scaffold design, cells used for seeding, and culturing conditions, to obtain the most robust valve for implantation [7].

As the heart valve is a highly mechanical tissue, exposed to both flow and stretch, important improvements in tissue structural integrity were made when cell culture of the scaffolds was performed under mechanical stimulation, resulting in improved cell and ECM organization leading to better mechanical performance [6]. Although these studies were instrumental in advancing the development and understanding of TEHV technology, these living valves have several practically insurmountable challenges: strict regulations around therapies with living material, the complexity of in vitro culturing, and the logistical problems due to the inability to store valves all make it difficult to commercially implement the TEHV as heart valve therapy. These challenges are currently addressed in two ways, either by treating the TEHV with a decellularization step (dTEHV), or by implanting a scaffold graft directly into the patient for in situ conversion into a living tissue by the host's cells (in situ TEHV). Decellularization removes the native cells and preserves the ECM generated in an in vitro bioreactor [8]. Cells from the host infiltrate the graft and form a novel autologous living heart valve. Before implantation, the dTEHVs can be stored and therefore are easier to translate to the clinic. The partial degradation of scaffold material and biological functionalization with ECM of the graft in the bioreactor prepares the dTEHV optimally for biocompatibility at implantation. Both in ovine and nonhuman primate models, these dTEHV have successfully replaced pulmonary heart valves with in vivo functionality of up to 24 weeks [9, 10••]. Still, the logistics of generating dTEHVs is complex and costly due to the bioreactors. To prevent this complexity, the therapy of cell-free, fully synthetic, in situ TEHV is now gaining momentum.

For in situ TEHV, the main advantage is that no in vitro culture is required at all. The lack of biological components on the scaffold reduces the immunogenicity of the in situ TEHV. A main drawback is that the formation of the novel tissue depends on the intrinsic regenerative capacity of the host. Especially in cases of congenital heart valve disease, metabolic disease, or immunologic defects, this may result in disrupted formation of tissue [11]. There has been much progress in defining the production conditions of both dTEHV and in situ TEHV that result in functionality in vivo, but this is a multiscale challenge, wherein mechanistic understanding of the contribution of all the biological, chemical, and mechanical contributors to the regenerating 
heart valve niche is virtually missing. Therefore, it is imperative to supplement the macroscopic understanding of heart valve mechanics and biological processes with the microscopic understanding of cellular biology, cellular signaling, and mechanics, leading to a homeostatic tissue. Important progress in in situ TEHV was recently published in a study in sheep, that showed stability and functionality of in situ TEHV at 12 months after implantation, without formation of pathological calcifications $[12 \bullet \bullet]$.

This review aims to address the current challenges of present TEHV strategies, which remain to be overcome in order to achieve successful translation of TEHV to the clinic (Fig.1).

\section{Challenges of in situ TEHV translation}

\section{Patient-related challenges to tissue engineered heart valves}

The concept of in situ tissue engineering depends on both the materials used to build the grafts and the host response to the implanted graft. Considering that the complete cellular contents of a self-seeding graft are derived from the recipient, the quality of these cell sources will directly influence the success rate of the grafts. A major challenge to tissue engineering strategies is to determine which patient-related factors will influence the process of repopulating the cellfree grafts in situ, and how to anticipate these factors in the design of the graft. Though the precise origin and character of the cellular response to scaffold material is difficult to define, it is generally assumed that a population of

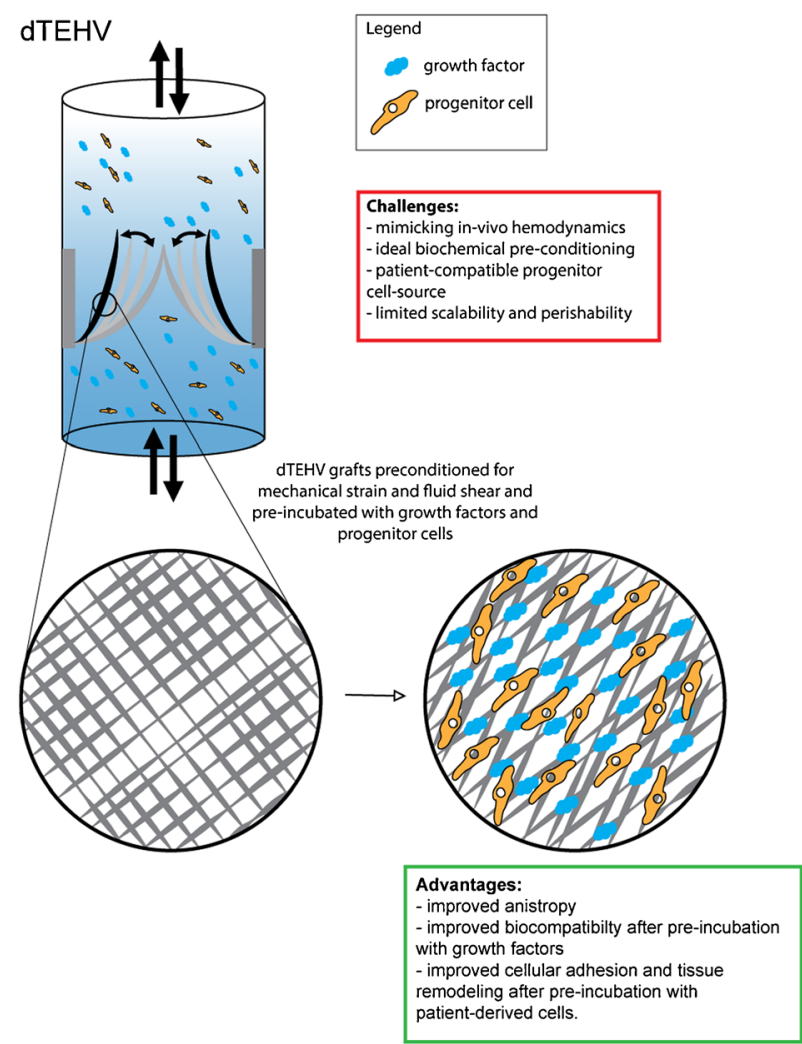

In-Situ TEHV

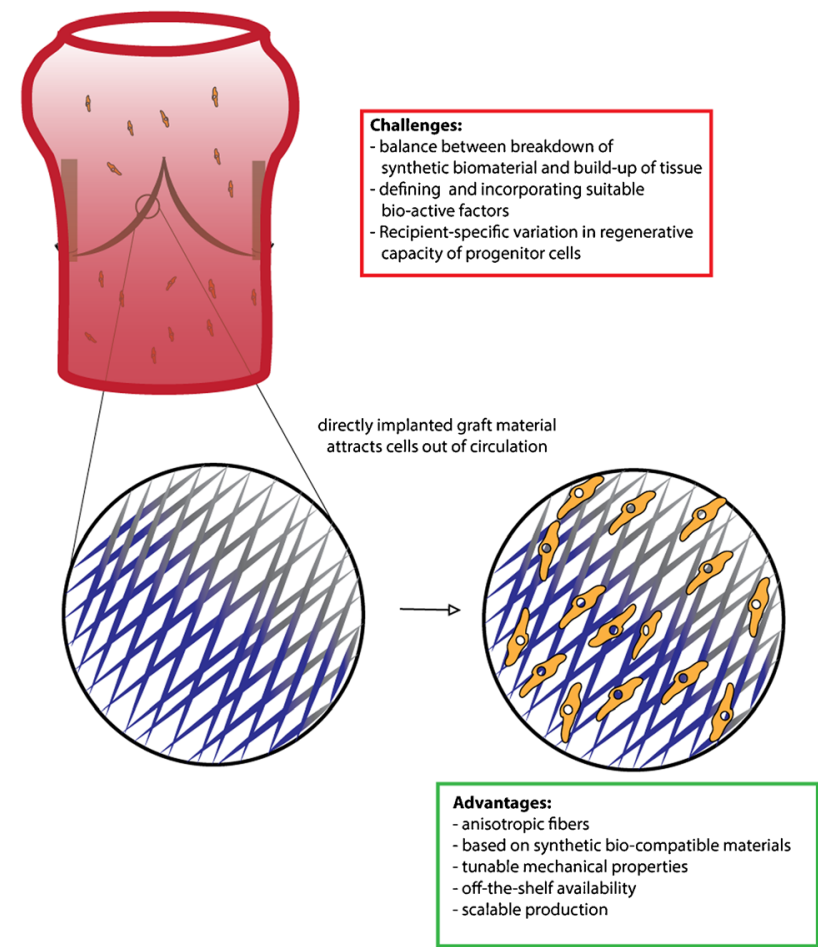

Fig. 1. dTEHV and in situ TEHV. 
progenitor cells will be required to achieve the development of a living heart valve replacement. A number of risk factors have been associated with impaired function of progenitor cells in those patient populations that will benefit from cardiovascular tissue engineered grafts. Risk factors such as diabetes mellitus and age are associated with lower levels of circulating progenitor (CD34+) cells [13].These risk factors may have a direct effect on the functionality of the progenitor cells, reducing their migratory or prolific capacity $[13,14]$. Progenitor cells derived from patients with type II diabetes adhere less well to endothelial cells and are less capable of participating in the formation of vascular structures in Matrigel assays [15]. In self-seeding grafts, cell migration is paramount to the repopulation of the cell-free materials. Cellular migration is related to the number of CD34+ cells, which are significantly lower in smokers and individuals with a family history of coronary artery disease [14]. Any patient-related factor that will impede progenitor migration is therefore a major challenge to the success of TEHVs, if not accounted for properly.

A patient population that might benefit greatly from living cardiovascular replacement grafts are patients with congenital disease. Encouragingly, there is evidence that children have significantly higher levels of CD34+/KDR+ cells, suggesting a greater capacity for regeneration and possibly a higher likelihood of successfully populating cell-free grafts [16]. In mature patients, there may be a potential for maximizing the number and function of progenitor cells prior to implanting cell-free grafts by administering mobilizing agents. Granulocyte colony stimulating factor has previously been administered to patients to maximize the CD34+ cell response to myocardial infarction. A tripling was found of the maximum white blood cell count with a 5 to 7 fold increase in CD34 cells after a 4 to 5 day treatment schedule. While this increase did not significantly improve left ventricular function in this study, it demonstrates that increasing the number of $\mathrm{CD} 34+$ progenitor cells in mature patients is feasible and safe [17]. Screening and potentially pre-treatment of patients prior to implantation of TEHVs, therefore, will likely be an important step in bringing tissue-engineered cardiovascular grafts to the clinic.

The cellular niche is the most important contributor to the tissue formation of a TEHV. A great diversity of circulating cells come into contact with the scaffold after implantation, and the respective contribution of the different cell types to tissue generation is only beginning to be understood. For many different tissue engineering applications, the first reaction after implantation is the infiltration of immune cells initiating a foreign body response. Infiltrating monocytes/ macrophages can subsequently assume a phenotype on a spectrum ranging from pro-inflammatory cells to tissue regenerating cells, the M1 to M2 phenotype. In this simplified characterization classical, interferon- $\gamma$ activated, M1macrophages represent the inflammatory end of the spectrum, whereas alternatively, interleukin- 4 activated, M2-macrophages represent the regenerating end, although current insights reveal the need for characterization by molecularly defined complex activation states [18]. These immune cells will slowly degrade the scaffold material and replace it with tissue. Engineering methods to control this balance to standardize patient outcome is vital. Traditionally, cytokines such as interleukins and IFN $\gamma$ play an important role in directing 
macrophage fate [18], but other signaling pathways are also involved. For instance, a recent study in a mice myocardial infarction model revealed that removing a Wnt transporter, Wntless, results in a shift towards M2 macrophages leading to increased angiogenesis in the infarct region [19]. The Notch signaling pathway is also involved in macrophage polarization. Activation of the pathway is associated with M1 polarization and can even overrule other cytokine inducers applied [20, 21]. This has been successfully investigated as a possible therapeutic target in reducing vein graft failure. Targeting Dll4 of either endothelial or macrophage origin, indicated that the Dll4 presented by macrophages contributed to vein graft lesions [22]. This exemplifies that macrophage fate can be controlled in many ways; however, the successful and robust implementation of this control requires clever biological engineering and thorough testing.

Early tissue formation ideally transitions into stable tissue, leading to a homeostatic valve that mimics the native, healthy valve as closely as possible. In the native valve, the main cell types are the valvular endothelial cells (VECs) and the valvular interstitial cells (VICs). The interaction between VECs and VICs maintains the structural integrity of the native heart valve. Both VECs and VICs come in a multitude of different phenotypic variants, with five VIC subtypes described with various functions in development, physiology and pathology $[23,24]$. In vivo experiments with dTEHV show that at stages of 4 weeks valves are already partially lined with endothelium and the interstitium contains vimentin positive, $\alpha \mathrm{SMA}$ negative cells, possibly indicative of quiescent fibroblast-like cells, although $\alpha \mathrm{SMA}$ positive cells are also seen indicating the

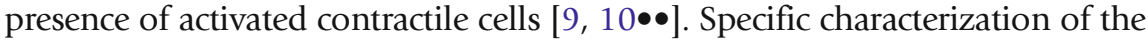
specific cell type in the interstitium is challenging. How the transition from early tissue formation to a mature valve takes place is poorly understood, but may be initiated by endothelialization from circulating endothelial progenitor cells, followed by endothelial to mesenchymal transition (EndoMT). The process of EndoMT also plays an important role in both early and late stages of native valve development $[25,26]$. If early stages of tissue formation can be controlled, it is possible that the subsequent maturation of the in situ TEHV introduces less variation across patients; however, experiments to test this are complex. As the scaffold is already partially degraded at these stages, this step in the tissueforming process is more difficult to control from the scaffold design and may require pharmacological interventions that in their turn are more difficult to specifically deliver to the heart valve niche.

Heart valves are tissues that are highly exposed to mechanical cues. During each cardiac cycle, the valves ensure the correct direction of the blood flow through the heart's atria and ventricles. Alternating systole and diastole creates pressure gradients across the valves. When this gradient is against the correct flow direction, the valves close and are stretched, stopping the blood flow. When the pressure gradient is in the correct flow direction, the valves open, blood flows through the orifice and stretch on the leaflets is released. After implantation of an in situ TEHV, the scaffold material is the main load-bearing structure. As the material is degraded and replaced by ECM and cells, the mechanical properties of the valve change, but integrity has to be maintained throughout the whole process. As the ECM becomes the load-bearing component of the 
valve, these loads have continuous effect on the organization of cells and the remodeling of the ECM, similar to the native heart valve [27]. This has large effects on the mechanical cues experienced by the cells in these valves. To mimic these conditions and to precondition TEHV and dTEHV for implantation, in vitro bioreactors are implemented that mechanically load the tissue. In vivo experiments, however, resulted in regurgitation and leaflet retraction $[28,29]$. Leaflet retraction in TEHV and dTEHV is an effect of the imbalance of the load exerted on the valve under diastole and the contractility and anisotropy of the cells in the leaflets [30]. Approaches to understand these effects through computational modeling revealed fundamental improvements of design to minimize regurgitation through balancing of hemodynamic forces and tissue organization. Subsequent redesigning of valve geometry and tissue anisotropy have led to improved valve coaptation area and tissue stability and may highlight the way forward in obtaining ideal valve design $[31,32 \bullet]$. How the balance of macroscopic and microscopic forces affects in situ TEHV remains to be investigated.

Several studies investigated the cellular mechanisms pathways in cells responding to mechanical forces as predictors of cell fate, as mechanical cues can contribute to pathological states of the cells $[33,34]$.

The Notch signaling pathway, mentioned before in macrophage polarization, is emerging now as a possible mediator of mechanotransduction. The Notch signaling pathway is a direct cell-cell contact signaling pathway of great importance in general organization of tissues, especially cardiovascular development. Notch is known to be crucial in various stages of heart valve biology, initially in the formation of endocardial cushions and control of EndoMT, up to the maintenance of cells in non-calcific state in the mature valve [26]. Defects in the Notch signaling pathway, both in the receptors (Notch 1-4), the ligands (Jag1 and 2, Dll1, 3 and 4), as well as the effector genes (Rbpjk) result in congenital defects including outflow tract malformations and heart valve defects [35]. Notch1 was the first gene found to cause familial BAV and calcific AoVD [36]. Defects in Notch signaling alter cellular response in both to VICs under strain and VECs under shear forces, predisposing cells for a calcific fate $[37,38]$. This is in line with other tissues where the Notch signaling pathway is directly responsive to mechanical cues, although the functional outcome varies across tissues, indicating complex regulatory mechanisms [39, 40]. Altered cellular responses to mechanical cues in tissue-forming cells with Notch defects make this another example of congenital defects that may complicate the implementation of in situ TEHV.

Another way to guide the tissue formation, in addition to preconditioning the patient to mobilize the proper cell populations, is by modifying material to be optimally suited to guide tissue formation through cell fate choices. The main body of research into bioactivating polymeric materials has focused on reproducing extracellular matrix elements such as collagens [41] and glycosaminoglycans [42] capable of adhering cells [43]. This approach is based on the concept that tissues derive their mechanical and biological characteristics from a cellular population on one hand, and a structural matrix to adhere to on the other. In in situ tissue engineering, however, a third element, namely that of 
novel tissue development, plays a major role. A very high level of tissue development is needed to produce enough ECM to fully take over from polymeric graft material and stimulate and maintain a cellular population. The requirements of in situ tissue engineered grafts have a lot in common with wound healing and tissue repair. Choosing candidates for bioactivity in cell-free constructs, therefore, should be based not only on cellular adhesion but also focus on triggering the developmental cues required to build up a fully functional biological tissue from scratch. Inspiration for biologically active molecules that may help orchestrate an appropriate tissue development may be found in repair processes such as ischaemic damage, which is known to trigger the mobilization and homing of cell populations capable of regenerating tissue and repairing damage [44]. Chemokines are molecules that are capable of both inducing cellular migration and cellular development. Proteins such as stromal cell-derived factor 1a (SDF1a) and monocyte chemoattrative protein1 (MCP1)


46]. Targeting Notch is notoriously difficult due to aspecificity following from the multitude of receptors and ligands involved and the risk of off-target effects, but novel engineered peptides may hold potential for harnessing these developmental signals $[47 \bullet, 48]$. In addition, factors such as platelet-derived growth factor PDGF [49] and vascular endothelial growth factor (VEGF) [50] show promising results in incorporating specific bioactivity into synthetic materials using a wide range of delivery methods [44]. An exciting though challenging aspect of in situ tissue engineering is the search for molecules that both attract and orchestrate populations of cells to go through the developmental stages of building up a previously non-existent living tissue.

When moving from in vitro engineered dTEHV to in situ TEHV, the challenges for the scaffolds used become apparent. Importantly, the biological processes related to valvular tissue formation and regeneration need to be stimulated, orchestrated, and controlled with a single, non-living and preferably degrading scaffold. From a materials point of view, these challenges are multidimensional. At the microscopic level, it is necessary to build the right niche for spatiotemporal control of cell recruitment, behavior (proliferation, differentiation, matrix production), quiescence, maintenance, and growth. This can be done via manipulating the biological, biochemical, and biophysical properties of scaffolds in close interplay with physiological environments [51]. The final purpose being to guide the tissue towards the functional layers found in the native heart valve, the ventricularis, fibrosa, and spongiosa, and the corresponding cell/ECM composition of these layers.

On the mesoscale level, it is important to control scaffold mechanical behavior. Opening and closing of the valve induce local deformations, and the stress distribution across the valve and subsequent anisotropy can make the difference between a regurgitating or a tightly sealed valve. The scaffolds degradation rate is of importance to maintain integrity in early stages of tissue formation and is mainly dependent on materials and processing: e.g., electrospinning, printing, or molding.

At the macroscale level, the handling and implantation of the scaffold are relevant during surgery, either as a surgical implant or minimally invasive 
delivery, e.g., as transcatheter valve replacement [52]. In the case of minimally invasive delivery, after implantation, the valve has to deploy from the shape of delivery into its functional shape. These properties are difficult to control with decellularised matrices, but synthetic matrices can offer full control at each length scale and with extraordinary reproducibility.

\section{Challenges in modeling tissue regeneration}

To accelerate the process of material design across length scales, bioengineering approaches like high-throughput analysis are crucial. In vivo experiments need to be the last step before translation occurs. But much information on the posed challenges can be obtained in vitro. Particularly, when looking at tissue regeneration, in vitro studies are important. Valvular tissue regeneration can be defined as the mechanism of maintaining valvular structural integrity by valvular cells. The process of activating and de-activating VICs, responsible for remodeling the valve ECM, is key to maintaining tissue homeostasis, and thus, also a vital challenge to understand when engineering a heart valve.

In vitro models allow for more accurate isolation and manipulation of independent variables controlling tissue formation, however, not in its traditional form. In vitro systems have typically used Petri dishes to study the role of the valvular cell populations and its role in tissue formation. However, the intrinsic unnatural environment of stiff substrates, and the two-dimensional environment that cultured cells reside in limits this approach. As described earlier, VICs harbor a great degree of mechanosensitivity, leading to uncontrollable phenotypic changes in two-dimensional culture systems [53]. As such, the field has looked at developing three-dimensional in vitro systems able to not only independently modulate the VIC and VEC phenotype, but also simulate the entire cellular driven process of valve homeostasis. Such a threedimensional in vitro approach will allow to study the native valve tissue formation outside of the human body, ultimately providing us with a much needed map of guiding human tissue formation.

To overcome this challenge, hydrogel micro-engineering has emerged. Hydrogels can be designed using natural proteins, such as collagen, hyaluronic acid, and elastin, to recapitulate vital environmental cues in native tissues [5456]. Hydrogels have yielded a great deal of interest due to their ability to be chemically and mechanically tailored to specific needs, and in this case, understanding valvular tissue formation.

Mounting evidence has shown that mechanical properties of the hydrogel can activate and modify intracellular pathways and alter VIC function. To this end, hydrogel studies have shown to maintain a quiescent VIC culture in threedimensional cultures, similar to a healthy native valve $[55,56]$. Controlling the mechanics and substrate stiffness in these three-dimensional models identified the PI3/AKT pathway as an elasticity sensitive pathway important for preservation of native VIC phenotype [57]. Conversely, changing hydrogel substrate and mechanics, mechanisms of myofibroblast activation of VICs have been elucidated. Shear stress [58, 59], changes in substrate stiffness [60], cellular proxim-


all contribute to the activation of VICs.

Not only understanding what leads to ECM deposition by VICs in native tissue, is key to understand neo-tissue formation in a TEHV, but also what is 


\section{Table 1. Identified challenges in the translation of (in situ) tissue-engineered heart valves}

\begin{tabular}{ll}
\hline $\begin{array}{l}\text { Origin of challenge } \\
\text { Patient }\end{array}$ & Nature of challenge \\
Patient & Variations in regenerative capacity make outcomes of valve engineering unpredictable \\
Early tissue formation & Finding ways to mobilize the proper cell population to kickstart tissue regeneration \\
Late tissue formation & Valve must stay intact throughout scaffold degradation/tissue formation \\
Transition of early to late & Reaching a steady state of tissue growth, apoptosis, remodeling, and quiescence \\
tissue formation & $\begin{array}{c}\text { Guiding the process of early formation to such an extent that healthy late tissue } \\
\text { formation builds upon the early tissue in all patients }\end{array}$ \\
Material & $\begin{array}{c}\text { Identifying and controlling the biomechanical cues that can guide cell fate based on } \\
\text { material mechanical or topological properties }\end{array}$ \\
Material & $\begin{array}{c}\text { Choosing the bioactive compounds that benefit the maximum amount of patients by } \\
\text { standardizing the tissue generating process by attracting cells and guiding cell fate } \\
\text { Finding the material that has all the required properties: optimal robustness in handling } \\
\text { and implantation, correct degradation rate, while allowing incorporation of } \\
\text { topological, biomechanical and biochemical cues } \\
\text { Controlling the relevant variables for understanding and ultimately predicting the impact } \\
\text { of TEHV designs and therapies on outcomes }\end{array}$
\end{tabular}

needed to maintain a healthy tissue homeostasis, and thus preventing activated cells to keep depositing ECM, reminiscent of fibrosis. Furthermore, most threedimensional culture systems utilize a single natural protein, such as collagen or hyaluronic acid, and work remains to be done to combine all native natural valve proteins into one three-dimensional culture system reminiscent of the heart valve ECM. In addition, challenges remain to simulate the valvular hemodynamic environment in a three-dimensional culture system. To this end, organ-on-a-chip technology and different pulsatile bioreactors are being developed.

\section{Conclusion}

TEHV differs vastly from the current standard of mechanical implants or allografts, bringing new perspectives and challenges to overcome (Table 1). Challenges arise from the complexity of the regeneration process. Patient variation and comorbidity affecting regeneration, the multiple phases in tissue formation, and the limited control that can be exerted on the regeneration process by incorporating guiding cues in the scaffold are the main challenges to be overcome. Considering the current treatments are lifesaving, the strongest challenge perhaps is that the TEHV will have to perform at least as good as the current treatments, with less complications such as the use of anticoagulation or reoperation. Translation of TEHV of all types to the clinic will remain a process with uncertainties, due to the large differences between the large animal models and the patient. Using models where variables of interest can be controlled tightly, and wherein complex mixtures of cell populations similar to those encountered in the regenerating valve can be cultured, we expect that all 
challenges can be overcome and the TEHV will become a novel lifesaving therapy.

\section{Acknowledgements}

O.S. received funding in project ImaValve, that was funded by the European Union's Seventh Framework Programme for research, technological development and demonstration under grant agreement no 604514 .

\section{Compliance with Ethical Standards}

\section{Conflict of Interest}

The authors declare that they have no conflicts of interest.

Human and Animal Rights and Informed Consent

This article does not contain any studies with human or animal subjects performed by any of the authors.

\section{Open Access}

This article is distributed under the terms of the Creative Commons Attribution 4.0 International License (http://creativecommons.org/licenses/by/4.0/), which permits unrestricted use, distribution, and reproduction in any medium, provided you give appropriate credit to the original author(s) and the source, provide a link to the Creative Commons license, and indicate if changes were made.

\section{References and Recommended Reading}

Papers of particular interest, published recently, have been highlighted as:

- Of importance

$\bullet \quad$ Of major importance

1. Iung B, Vahanian A. Epidemiology of acquired valvular heart disease. Can J Cardiol 2014; 30:962-970.

2. Gammie JS, Sheng S, Griffith BP, Peterson ED, Rankin JS, O'Brien SM, et al. Trends in mitral valve surgery in the United States: results from the Society of Thoracic Surgeons Adult Cardiac Database. Ann Thorac Surg. 2009;87:1431-9.

3. Pibarot P, Dumesnil JG. Prosthetic heart valves: selection of the optimal prosthesis and long-term management. Circulation. 2009;119:1034-48.

4. Kobayashi J. Stentless aortic valve replacement: an update. Vasc Health Risk Manag. 2011;7:345-51.

5. Eberl T, Siedler S, Schumacher B, Zilla P, Schlaudraff K, Fasol R. Experimental in vitro endothelialization of cardiac valve leaflets. Ann Thorac Surg. 1992;53:487-92.

6. Hoerstrup SP, Sodian R, Daebritz S, Wang J, Bacha EA, Martin DP, et al. Functional living trileaflet heart valves grown in vitro. Circulation. 2000;102:III44-9.
7. Mol A, Smits AIPM, Bouten CVC, Baaijens FPT. Tissue engineering of heart valves: advances and current challenges. Expert Rev Med Devices. 2009;6:259-75.

8. Dijkman PE, Driessen-Mol A, Frese L, Hoerstrup SP, Baaijens FPT. Decellularized homologous tissueengineered heart valves as off-the-shelf alternatives to xeno- and homografts. Biomaterials. 2012;33:454554.

9. Driessen-Mol A, Emmert MY, Dijkman PE, Frese L, Sanders B, Weber B, et al. Transcatheter implantation of homologous "off-the-shelf" tissue-engineered heart valves with self-repair capacity: long-term functionality and rapid in vivo remodeling in sheep. J Am Coll Cardiol. 2014;63:1320-9.

10.• Weber B, Dijkman PE, Scherman J, Sanders B, Emmert MY, Grünenfelder J, et al. Off-the-shelf human decellularized tissue-engineered heart valves in a nonhuman primate model. Biomaterials. 2013;34:7269-80. 
This study describes the implantation of decellularized TEHVs into a non-human primate, showing fast recellularization in contrast to human decellularized native heart valve transplants. Noteable is that distinct from the ovine model, leaflet thickening did not occur in the non-human primate, although leaflet retraction occurred in both models

11. Kehl D, Weber B, Hoerstrup SP. Bioengineered living cardiac and venous valve replacements: current status and future prospects. Cardiovasc Pathol Off J Soc Cardiovasc Pathol. 2016;25:300-5.

12.• Kluin J, Talacua H, AIPM S, Emmert MY, MCP B, Fioretta ES, et al. In situ heart valve tissue engineering using a bioresorbable elastomeric implant-from material design to 12 months follow-up in sheep. Biomaterials. 2017;125:101-17.

In this study the succesfull implementation of in situ TEHV in sheep is described from material design up to 12 monthfollow up, showing absence of calcification pathology, 12 month functionality and progressing replacement of the synthetic valve by tissue.

13. Zhang L, Wang R, Xiao C-S, Wu Y, Gao C-Q. Relationship between perioperative cardiovascular risk factors and bone marrow cells from patients undergoing coronary artery bypass grafting surgery. Genet Mol Res GMR. 2015;14:15,233-41.

14. Vasa M, Fichtlscherer S, Aicher A, Adler K, Urbich C, Martin $\mathrm{H}$, et al. Number and migratory activity of circulating endothelial progenitor cells inversely correlate with risk factors for coronary artery disease. Circ Res. 2001;89:E1-7.

15. Tepper OM, Galiano RD, Capla JM, Kalka C, Gagne PJ, Jacobowitz GR, et al. Human endothelial progenitor cells from type II diabetics exhibit impaired proliferation, adhesion, and incorporation into vascular structures. Circulation. 2002;106:2781-6.

16. Jie KE, Goossens MHJ, van Oostrom O, Lilien MR, Verhaar MC. Circulating endothelial progenitor cell levels are higher during childhood than in adult life. Atherosclerosis. 2009;202:345-7.

17. Ellis SG, Penn MS, Bolwell B, Garcia M, Chacko M, Wang T, et al. Granulocyte colony stimulating factor in patients with large acute myocardial infarction: results of a pilot dose-escalation randomized trial. Am Heart J. 2006;152(1051):e9-14.

18. Murray PJ, Allen JE, Biswas SK, Fisher EA, Gilroy DW, Goerdt S, et al. Macrophage activation and polarization: nomenclature and experimental guidelines. Immunity. 2014;41:14-20.

19. Palevski D, Levin-Kotler L-P, Kain D, Naftali-Shani N, Landa N, Ben-Mordechai T, et al. Loss of macrophage Wnt secretion improves remodeling and function after myocardial infarction in mice. J Am Heart Assoc. 2017:6.

20. Fukuda D, Aikawa E, Swirski FK, Novobrantseva TI, Kotelianski V, Gorgun CZ, et al. Notch ligand delta-like 4 blockade attenuates atherosclerosis and metabolic disorders. Proc Natl Acad Sci U S A. 2012;109:E1868-77.

21. Wang Y-C, He F, Feng F, Liu X-W, Dong G-Y, Qin H-Y, et al. Notch signaling determines the M1 versus $M 2$ polarization of macrophages in antitumor immune responses. Cancer Res. 2010;70:4840-9.

22. Koga J, Nakano T, Dahlman JE, Figueiredo J-L, Zhang $\mathrm{H}$, Decano J, et al. Macrophage Notch ligand Delta-like 4 promotes vein graft lesion development: implications for the treatment of vein graft failure. Arterioscler Thromb Vasc Biol. 2015;35:2343-53.

23. Liu AC, Joag VR, Gotlieb AI. The emerging role of valve interstitial cell phenotypes in regulating heart valve pathobiology. Am J Pathol. 2007;171:1407-18.

24. Bischoff J, Casanovas G, Wylie-Sears J, Kim D-H, Bartko PE, Guerrero JL, et al. CD45 expression in mitral valve endothelial cells after myocardial infarction. Circ Res. 2016;119:1215-25.

25. Armstrong EJ, Bischoff J. Heart valve development: endothelial cell signaling and differentiation. Circ Res. 2004;95:459-70.

26. Wirrig EE, Yutzey KE. Conserved transcriptional regulatory mechanisms in aortic valve development and disease. Arterioscler Thromb Vasc Biol. 2014;34:737-41.

27. Oomen PJA, Loerakker S, van Geemen D, Neggers J, Goumans $\mathrm{M}-\mathrm{JTH}$, van den Bogaerdt AJ, et al. Agedependent changes of stress and strain in the human heart valve and their relation with collagen remodeling. Acta Biomater. 2016;29:161-9.

28. Syedain ZH, Lahti MT, Johnson SL, Robinson PS, Ruth GR, Bianco RW, et al. Implantation of a Tissue-engineered Heart Valve from Human Fibroblasts Exhibiting Short Term Function in the Sheep Pulmonary Artery. Cardiovasc Eng Technol. 2011;2:101-12.

29. Schmidt D, Dijkman PE, Driessen-Mol A, Stenger R, Mariani C, Puolakka A, et al. Minimally invasive implantation of living tissue engineered heart valves: a comprehensive approach from autologous vascular cells to stem cells. J Am Coll Cardiol. 2010;56:510-20.

30. van Loosdregt IAEW, Argento G, Driessen-Mol A, Oomens CWJ, Baaijens FPT. Cell-mediated retraction versus hemodynamic loading - a delicate balance in tissue-engineered heart valves. J Biomech. 2014;47:2064-9.

31. Loerakker S, Argento G, Oomens CWJ, Baaijens FPT. Effects of valve geometry and tissue anisotropy on the radial stretch and coaptation area of tissue-engineered heart valves. J Biomech. 2013;46:1792-800.

32. Sanders B, Loerakker S, Fioretta ES, Bax DJP, DriessenMol A, Hoerstrup SP, et al. Improved geometry of decellularized tissue engineered heart valves to prevent leaflet retraction. Ann Biomed Eng. 2016;44:1061-71. In this study computation of the interplay between leaflet geometry and forces lead to a novel design imposed on the valve by a bioreactor insert that reduces in vitro regurgitation and leaflet retraction

33. Gupta V, Werdenberg JA, Lawrence BD, Mendez JS, Stephens EH, Grande-Allen KJ. Reversible secretion of glycosaminoglycans and proteoglycans by cyclically stretched valvular cells in 3D culture. Ann Biomed Eng. 2008;36:1092-103. 
34. Schoen FJ. Evolving concepts of cardiac valve dynamics. The Continuum of Development, Functional Structure, Pathobiology, and Tissue Engineering. Circulation. 2008;118:1864-80.

35. Luxán G, D'Amato G, MacGrogan D, de la Pompa JL. Endocardial Notch signaling in cardiac development and disease. Circ Res. 2016;118:e1-18.

36. Garg V, Muth AN, Ransom JF, Schluterman MK, Barnes $\mathrm{R}$, King IN, et al. Mutations in NOTCH1 cause aortic valve disease. Nature. 2005;437:270-4.

37. Chen J, Ryzhova LM, Sewell-Loftin MK, Brown CB, Huppert SS, Baldwin HS, et al. Notch1 mutation leads to valvular calcification through enhanced myofibroblast mechanotransduction. Arterioscler Thromb Vasc Biol. 2015; ATVBAHA.114.305095.

38. Theodoris CV, Li M, White MP, Liu L, He D, Pollard KS, et al. Human disease modeling reveals integrated transcriptional and epigenetic mechanisms of NOTCH1 haploinsufficiency. Cell. 2015;160:1072-86.

39. Esteves de Lima J, Bonnin M-A, Birchmeier C, Duprez D. Muscle contraction is required to maintain the pool of muscle progenitors via YAP and NOTCH during fetal myogenesis. eLife. 2016; 5.

40. Samsa LA, Givens C, Tzima E, Stainier DYR, Qian L, Liu J. Cardiac contraction activates endocardial Notch signaling to modulate chamber maturation in zebrafish. Dev Camb Engl. 2015;142:4080-91.

41. Han S, Shin Y, Jeong HE, Jeon JS, Kamm RD, Huh D, et al. Constructive remodeling of a synthetic endothelial extracellular matrix. Sci Rep. 2015;5:18290.

42. Zhang J, Wang J, Wei Y, Gao C, Chen X, Kong W, et al. ECM-mimetic heparin glycosamioglycanfunctionalized surface favors constructing functional vascular smooth muscle tissue in vitro. Colloids Surf B: Biointerfaces. 2016;146:280-8.

43. Williams PA, Silva EA. The role of synthetic extracellular matrices in endothelial progenitor cell homing for treatment of vascular disease. Ann Biomed Eng. 2015;43:2301-13.

44. Muylaert DEP, Fledderus JO, Bouten CVC, Dankers PYW, Verhaar MC. Combining tissue repair and tissue engineering; bioactivating implantable cell-free vascular scaffolds. Heart Br Card Soc. 2014;100:1825-30.

45.• DEP M, van Almen GC, Talacua H, Fledderus JO, Kluin J, SIS H, et al. Early in situ cellularization of a supramolecular vascular graft is modified by synthetic stromal cell-derived factor- $1 \alpha$ derived peptides. Biomaterials. 2016;76:187-95.

This study describes the design and incorporation of a biologically active peptide in an electrospun scaffold that recruits and directs tissue forming cells in rat vascular grafts. The peptide was engineered for incorporation in a supramolecular material, providing a modular approach allowing versatility in bioactives

46. Talacua H, Smits AIPM, Muylaert DEP, van Rijswijk JW, Vink A, Verhaar MC, et al. In Situ tissue engineering of functional small-diameter blood vessels by host circulating cells only. Tissue Eng Part A. 2015;21:2583-94.
47. Kangsamaksin T, Murtomaki A, Kofler NM, Cuervo H, Chaudhri RA, Tattersall IW, et al. NOTCH decoys that selectively block DLL/NOTCH or JAG/NOTCH disrupt angiogenesis by unique mechanisms to inhibit tumor growth. Cancer Discov. 2015;5:182-97.

In this study pharmacological control of specific subsets of the notch signalling pathway is achieved, a prerequisite for feasible targeting of this signalling pathway in therapies.

48. Cordle J, Johnson S, Zi Yan Tay J, Roversi P, Wilkin MB, de Madrid $\mathrm{BH}$, et al. A conserved face of the Jagged/ Serrate DSL domain is involved in Notch transactivation and cis-inhibition. Nat Struct $38 \mathrm{Mol}$ Biol. 2008;15:849-57.

49. Liebesny PH, Byun S, Hung H-H, Pancoast JR, Mroszczyk KA, Young WT, et al. Growth factormediated migration of bone marrow progenitor cells for accelerated scaffold recruitment. Tissue Eng Part A. 2016;22:917-27.

50. Dashnyam K, Jin G-Z, Kim J-H, Perez R, Jang J-H, Kim $\mathrm{H}-\mathrm{W}$. Promoting angiogenesis with mesoporous microcarriers through a synergistic action of delivered silicon ion and VEGF. Biomaterials. 2017;116:145-57.

51. Bouten CVC, Dankers PYW, Driessen-Mol A, Pedron S, Brizard AMA, Baaijens FPT. Substrates for cardiovascular tissue engineering. Adv Drug Deliv Rev. 2011;63:221-41.

52. Emmert MY, Weber B, Behr L, Sammut S, Frauenfelder $\mathrm{T}$, Wolint $\mathrm{P}$, et al. Transcatheter aortic valve implantation using anatomically oriented, marrow stromal cellbased, stented, tissue-engineered heart valves: technical considerations and implications for translational cellbased heart valve concepts. Eur J Cardio Thorac Surg Off J Eur Assoc Cardio Thorac Surg. 2014;45:61-8.

53. Hjortnaes J, Goettsch C, Hutcheson JD, Camci-Unal G, Lax L, Scherer K, et al. Simulation of early calcific aortic valve disease in a $3 \mathrm{D}$ platform: a role for myofibroblast differentiation. J Mol Cell Cardiol. 2016;94:13-20.

54. Hjortnaes J, Butcher J, Figueiredo J-L, Riccio M, Kohler $\mathrm{RH}$, Kozloff KM, et al. Arterial and aortic valve calcification inversely correlates with osteoporotic bone remodelling: a role for inflammation. Eur Heart J. 2010;31:1975-84.

55. Hjortnaes J, Camci-Unal G, Hutcheson JD, Jung SM, Schoen FJ, Kluin J, et al. Directing valvular interstitial cell myofibroblast-like differentiation in a hybrid hydrogel platform. Adv Health Mater. 2015;4:121-30.

56. Kirschner CM, Alge DL, Gould ST, Anseth KS. Clickable, photodegradable hydrogels to dynamically modulate valvular interstitial cell phenotype. Adv Health Mater. 2014;3:649-57.

57. Wang H, Tibbitt MW, Langer SJ, Leinwand LA, Anseth KS. Hydrogels preserve native phenotypes of valvular fibroblasts through an elasticity-regulated PI3K/AKT pathway. Proc Natl Acad Sci U S A. 2013;110:19336-41.

58. Richards J, El-Hamamsy I, Chen S, Sarang Z, Sarathchandra P, Yacoub MH, et al. Side-specific endothelial-dependent regulation of aortic valve calcification: interplay of hemodynamics and nitric oxide signaling. Am J Pathol. 2013;1(82):1922-31. 
59. Rathan S, Ankeny CJ, Arjunon S, Ferdous Z, Kumar S, Fernandez Esmerats J, et al. Identification of side- and shear-dependent microRNAs regulating porcine aortic valve pathogenesis. Sci Rep. 2016;6:25397.

60. Mabry KM, Lawrence RL, Anseth KS. Dynamic stiffening of poly (ethylene glycol)-based hydrogels to direct valvular interstitial cell phenotype in a three-dimensional environment. Biomaterials. 2015;49:47-56.

61.• Hjortnaes J, Shapero K, Goettsch C, Hutcheson JD, Keegan J, Kluin J, et al. Valvular interstitial cells suppress calcification of valvular endothelial cells. Atherosclerosis. 2015;242:251-60.
This study shows the interaction between VICs and VECs is a prominent factor in cell fate, highlighting the importance of understanding these interactions and of using models and bioreactors where this can be controlled

62. Tseng H, Balaoing LR, Grigoryan B, Raphael RM, Killian TC, Souza GR, et al. A three-dimensional co-culture model of the aortic valve using magnetic levitation. Acta Biomater. 2014;10:173-82.

63. Fisher CI, Chen J, Merryman WD. Calcific nodule morphogenesis by heart valve interstitial cells is strain dependent. Biomech Model Mechanobiol. 2013;12:517. 